\title{
HUBUNGAN ANTARA FAKTOR SUKU DAN USIA DENGAN KECENDERUNGAN PREFERENSI MASYARAKAT KALIMANTAN TIMUR TERHADAP KOMPONEN PRODUK FESYEN TAS
}

\author{
Dita Andansari \\ Staf Pengajar Program Studi Desain Produk Jurusan Desain \\ Politeknik Negeri Samarinda \\ e-mail: ditaandansari@yahoo.com \\ Darius Shyafary \\ Staf Pengajar Program Studi Desain Produk Jurusan Desain \\ Politeknik Negeri Samarinda \\ e-mail: dariussyafari@gmail.com
}

\begin{abstract}
ABSTRAK
Dalam mengembangkan sebuah produk, maka kesukaan (preferensi) dari masyarakat pengguna harus diperhatikan dengan seksama sehingga produk baru akan selalu laku di pasaran. Masyarakat pengguna produk dalam sebuah wilayah dapat berbeda antara wilayah yang satu dengan lainnya dalam hal heterogen atau tidaknya penduduknya. Hal ini dapat mempengaruhi juga preferensi masyarakat ketika memilih sebuah produk. Kesimpulan dari beberapa penelitian yang telah dilakukan menunjukkan bahwa budaya seseorang mempengaruhi tingkat preferensi/pilihan terhadap produk. Kontribusi industri fesyen terhadap PDB nasional sebesar 1,21 persen. Disebutkan bahwa dari 400ribu transaksi yang terjadi, yang paling tinggi adalah kategori fashion yang diminati di Indonesia. Tas wanita merupakan salah produk aksesoris fesyen yang mempunyai peluang untuk dikembangkan. Perlu dilakukan penelitian tentang hubungan antara suku dan usia dengan kecenderungan preferensi masyarakat Kalimantan Timur terhadap komponen produk fesyen tas.

Tujuan dari penelitian ini adalah Mengetahui apa saja preferensi komponen tas ulap doyo serta mengetahui adanya hubungan antara usia/suku dengan preferensi terhadap komponen tas ulap doyo. Metode yang dilakukan adalah deskriptif dengan bentuk single cross sectional dengan analisis crosstabulation dengan chi square.

Hasil dari penelitian ini adalah Sebagian besar responden didomnasi oleh usia remaja akhir (17-25 thn) dengan 76,4\%, Suku Jawa yaitu 22 orang dengan 30,6\%. Preferensi responden Handle tas yang disukai adalah rantai besi dianyam kulit (25\%), penutup tas yang disukai adalah tidak berpenutup depan sebesar 23,6\%, kantong dengan ritsleting sangat disukai yaitu 40,3\%, gusset/bagian sambungan samping tas dengan bentuk bidang diperluas ada ritsleting disukai sebesar 30,6\% serta material yang disukai adalah material gabungan ulap doyo dan kulit asli sebesar 54,2\%. Dari hasil pengolahan data, hanya terdapat 1 tabulasi silang yang signifikan, yaitu pada: Tingkat keterkaitan antara suku dengan bentuk kantong tas
\end{abstract}

Kata kunci : hubungan, suku, usia, preferensi, tas, Kalimantan Timur 
Vol. 7, No. 2, April 2020

\section{ABSTRACT}

The preferences of the user community must be considered carefully so that new products will always sell in the market. Product user communities in an area may differ from one region to another in terms of heterogeneity or whether or not the population. This can also affect people's preferences when choosing a product. The conclusions from several studies that have been done show that a person's culture influences the level of preference / choice of product. The contribution of the fashion industry to the national GDP of 1.21 percent. It was stated that of the 400 thousand transactions that occurred, the highest was the fashion category that was in demand in Indonesia. Women's bag is one of the fashion accessories products that have the opportunity to be developed. Research needs to be done about the relationship between ethnicity and age with the tendency of the preferences of the people of Kalimantan Timur for the component of bag fashion products.

The purpose of this study is to find out what are the preferences of doyo bag components and to know the relationship between age / ethnicity and the preferences of doyo bag components. The method used is descriptive with a single cross sectional form with crosstabulation analysis with chi square.

The results of this study were that the majority of respondents were dominated by their late teens (17-25 years) with 76.4\%, Javanese, namely 22 people with $30.6 \%$. Respondents' preferences Preferred bag handles are leather-woven iron chains (25\%), preferred bag closures are $23.6 \%$ unclosed, zippered pockets are preferred $40.3 \%$, gussets / side joints of bags with field shapes expanded there is a zipper preferred by $30.6 \%$ and the preferred material is a combined material of doyo wormwood and genuine leather by $54.2 \%$. From the results of data processing, there is only 1 significant cross tabulation, namely at: The level of interrelation between the tribes and the shape of the bag.

Keywords: relationship, ethnicity, age, preference, bag, Kalimantan Timur

\section{PENDAHULUAN}

Dalam mengembangkan sebuah produk, maka kesukaan (preferensi) dari masyarakat pengguna harus diperhatikan dengan seksama sehingga produk baru akan selalu laku di pasaran. Menurut Lee \& DeLong (2018) dalam penelitian yang berjudul Re-birthed fashion handbags as a collaborative design project, dapat disimpulkan bahwa hasil analisis desain yang dibuat kembali menunjukkan bahwa alasan paling umum untuk tidak dipilihnya produk di pasar adalah desain yang tidak perlu diperhatikan karena terlalu umum atau tidak berbeda dari barang serupa lainnya. Dalam kasus seperti itu, konsumen dapat mengganti desain dasar ini dengan produk merek yang lebih murah. Dengan demikian, desain tas fashion yang dibuat kembali diberi fitur desain yang unik dan utilitas yang dapat dikenali konsumen sebagai terkait dengan identitas merek. (Rebirthed fashion handbags as a collaborative design project,Yoon Kyung Lee \& Marilyn DeLong, 04 June 2018). Dari kesimpulan ini, terlihat bahwa fitur/ komponen produk merupakan salah satu hal penting dalam sebuah desain.

Masyarakat pengguna produk dalam sebuah wilayah dapat berbeda antara wilayah yang satu dengan lainnya dalam hal heterogen atau tidaknya penduduknya. Hal ini dapat mempengaruhi juga preferensi masyarakat ketika memilih sebuah produk. Menurut Raid \& Gopal (2014) dalam penelitian yang berjudul Study of consumer buying behavior on Branded ethnic apparel, menyimpulkan bahwa tingkah laku membeli konsumen ada hubungannya dengan kelompok umur, pendudukan (pekerjaan) 
Dita Andansari, Darius Shyafary, Hubungan Faktor Suku Dan Usia Dengan

Kecenderungan Preferensi Masyarakat Kalimantan Timur Terhadap Komponen

Produk Fesyen Tas

serta tidak ada hubungannya dengan jenis kelamin, pendapatan tahunan keluarga,dan wilayah. Menurut Leng \& Botelho (2010) dalam How does national culture impact on consumers decision-making style? a cross cultural study in Brazil, The United States an Japan, menyimpulkan bahwa ada perbedaan gaya pengambilan keputusan menurut budaya yang dimiliki konsumen. Dalam penelitiannya yang berjudul Hubungan Antara Faktor Penduduk Setempat Terhadap Kecenderungan Preferensinya ( Nofiawaty, 2010) menyimpulkan bahwa terdapat tingkat keterkaitan sebagai penduduk asli Palembang terhadap warna favorit, motif favorit, rasa makanan favorit serta tempat belanja favorit. Kesimpulan dari beberapa penelitian yang telah dilakukan menunjukkan bahwa budaya seseorang mempengaruhi tingkat preferensi/pilihan terhadap produk.

Menurut Menteri Perindustrian Airlangga Hartarto pada pembukaan Indonesia Fashion Week (IFW) 2017 di Jakarta, Rabu (1 Februauri 2017), bahwa Industri fesyen berkontribusi besar terhadap devisa negara, PDB nasional dan penyerapan tenaga kerja. Berdasarkan data BPS, nilai ekspor produk fesyen pada tahun 2015 mencapai USD12,11 miliar dengan pasar utama Amerika Serikat, Eropa dan Jepang. Selanjutnya, kontribusi industri fesyen terhadap PDB nasional sebesar 1,21 persen. Sedangkan, sebagai sektor padat karya, industri fesyen mampu menyerap tenaga kerja sebanyak dua juta orang atau 14,7 persen dari total tenaga kerja di sektor industri.

Adapun lima sektor industri pengolahan nonmigas yang mencatatkan nilai ekspornya paling besar pada tahun 2019, yakni industri makanan dan minuman yang mampu menembus hingga US\$ 27,28 miliar. Kemudian, industri logam dasar sebesar US\$ 17,37 miliar, serta industri tekstil dan pakaian jadi mencapai US\$ 12,90 miliar. (https://kemenperin.go.id/).

Salah satu marketplace online, Shopee, mengatakan bahwa transaksi tert- inggi yang tercatat di aplikasi mereka adalah kategori belanja fashion. Menurut Chris Feng selaku CEO Shopee, di Fairmount Hotel, Jumat (19/1/2018), yang masuk dalam kategori fashion dengan transaksi tertinggi adalah busana, sepatu, dan pelengkap tampilan lainnya. Disebutkan bahwa dari 400ribu transaksi yang terjadi, yang paling tinggi adalah kategori fashion yang diminati di Indonesia.

Seiring dengan perkembangannya, fashion tidak hanya didominasi oleh satu jenis produk yaitu pakaian saja, tetapi juga berkembang di dalamnya aksesoris seperti sepatu dan tas. Dari sejarah dapat dilihat, pada 1950-an, ledakan ekonomi pascaperang memicu revolusi mode, dipelopori oleh Tampilan Baru Dior. Gaun dengan model pinggang yang pas, rok panjang menyerempet pergelangan kaki, dan wanita membutuhkan tas tangan yang lebih kecil dan terstruktur untuk menyeimbangkan siluet baru ini. Sementara pada tahun 1980an, dengan gaya maksimalnya dan konsumerisme yang merajalela, merupakan masa kejayaan untuk fashion, dan tas tangan adalah cara tercepat untuk mengkomunikasikan gaya si pemiliknya. (https://www.vogue. co.uk/gallery/bag-trends-by-the-decade). Dengan demikian, tas wanita merupakan salah produk aksesoris fesyen yang mempunyai peluang untuk dikembangkan.

Andansari \& Keliwar (2019) dalam penelitian yang berjudul Pengembangan Desain Produk Fesyen Berbahan Ulap Doyo untuk Diaplikaskan di UKM Pokant Takaq, Tenggarong, Kalimatan Timur Guna Mendukung Sektor Pariwisata, dimana penekanannya pada komponen produk bahwa dari hasil kuesioner menunjukkan bahwa pilihan untuk komponen pegangan tas nilai tertinggi ada pada jenis pegangan ada ring, komponen penutup tas nilai tertinggi adalah jenis tutup depan setengah dengan kunci putar berkait, komponen kantong tas dengan ritsleting, sambungan samping tas dengan nilai tertinggi yaitu jenis sambungan dengan tali dan berkancing serta material 
Vol. 7, No. 2, April 2020

tas yang terpilih dengan nilai tertinggi adalah material gabungan kain tenun ulap doyo dan kulit asli. Dimana responden pengisi kuesioner dengan suku dan usia yang berbeda.

Dari latar belakang di atas, maka perlu dilakukan penelitian tentang hubungan antara suku dan usia dengan kecenderungan preferensi masyarakat Kalimantan Timur terhadap komponen produk fesyen tas.

\section{METODE}

Metode dalam penelitian ini adalah seperti berikut:

\section{Jenis Penelitian}

Dalam penelitian ini digunakan riset konklusif deskriptif dalam bentuk single cross sectional. Riset konklusif digunakan untuk menguji hiotesis spesifik dan menguji hubungannya. Riset deskriptif adalah penelitian dengan menjelaskan fungsi dan karakteristik responden dengan menggunakan data primer dan sekunder.

2. Lokasi Penelitian

Lokasi penelitian ini dilakukan di Kota Samarinda Provinsi Kalimantan Timut

3. Batasan Operasional

Aspek kependudukan yang dibahas dalam penelitian ini adalah aspek suku budaya dan usia. Komponen produk yang akan dibahas adalah komponen pegangan tas jenis pegangan ada ring, komponen penutup tas tutup depan setengah dengan kunci putar berkait, komponen kantong tas dengan ritsleting, sambungan samping tas dengan tali dan ber- kancing serta material tas adalah material gabungan kain tenun ulap doyo dan kulit asli

4. Populasi dan Sampel Penelitian

Populasi yang dipilih dalam penelitian ini adalah masyarakat Kalimantan Timur dengan range usia antara 17 sampai dengan 55 tahun, jenis kelamin perempuan, suku : Jawa, Dayak, Banjar, Bugis, Padang, Sunda, Kutai, dan Batak, sebanyak 72 responden.

5. Metode Pengumpulan Data Pengumpulan data pada penelitian ini dengan menyebarkan kuesioner.

6. Teknik Analisis Data

Teknik analisis data yang digunakan dalam penelitian ini menggunakan deskriptif kualitatif. Data yang ada diollah dengan menggunakan SPSS 17 dan kemudian dianalisis menggunakan perangkat analisis statistic cross tabulation dan kemudian hasilnya akan dianalisis untuk mendapatkan gambaran dari data yang terkumpul.

\section{PEMBAHASAN}

Analisis diawali dengan profil responden, dari hasil pengolahan tentang data responden, didapatkan profil responden sebagai berikut :

1. Usia responden remaja akhir (17-25 thn) sebanyak 76,4\% (55 orang), dewasa awal (26-35 thn) sebanyak 19,4\% (14 orang), dewasa akhir (36-45 thn) sebanyak $1,4 \%$ (1 orang) dan lansia awal (4655) sebanyak 2,8\% (2 orang).

Tabel 1. Usia

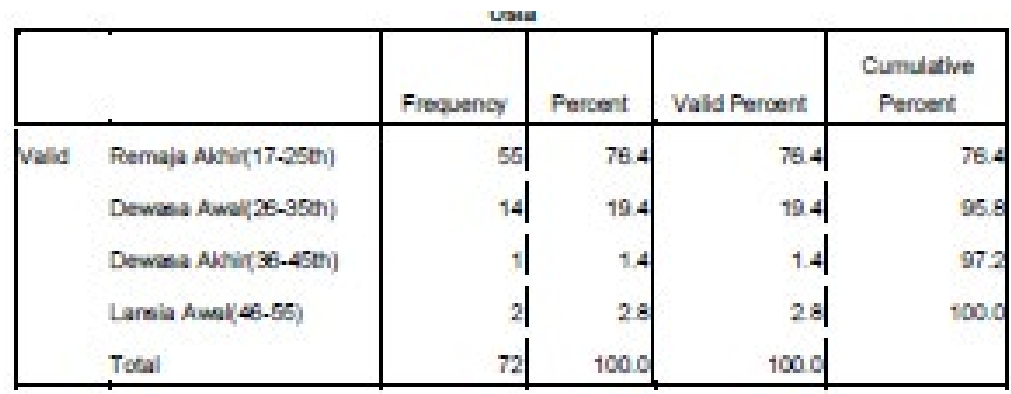


Dita Andansari, Darius Shyafary, Hubungan Faktor Suku Dan Usia Dengan Kecenderungan Preferensi Masyarakat Kalimantan Timur Terhadap Komponen

Produk Fesyen Tas

2. Suku Jawa sebanyak $30,6 \%$ (22 orang), Preferensi responden terhadap komponen Dayak sebanyak 4,2\% (3orang), Banjar sebanyak $25 \%$ (18 orang), Bugis sebanyak $12,5 \%$ (9 orang), Padang sebanyak $5,6 \%$ (4 orang), Sunda sebanyak 4,2\% (3 orang), Kutai sebanyak $11,1 \%$ (8 orang), dan Batak sebanyak 6,9\% (5 orang).

3. Remaja akhir suku Jawa 17 orang, Dayak 3 orang, Banjar 13 orang, Bugis 8 orang, Padang 4 orang, Kutai 7 orang dan Batak 3 orang. Dewasa awal terdiri dari suku Jawa 4 orang, Banjar 5 orang, Bugis 1 orang, Sunda 1 orang, Kutai 1 orang dan batak 2 orang. Dewasa akhir terdiri dari suku Sunda 1 orang. Lansia awal terdiri dari suku Jawa 1 orang, dan suku Sunda 1 orang.

tas wanita yaitu sebagai berikut :

\section{Berdasarkan USIA \\ Preferensi terhadap Handel Tas :}

Remaja akhir lebih menyukai handel tas jenis ada gesper dan ada ring, masing-masing 10 orang, Dewasa awal lebih menyukai Bentuk handle Tas ada gesper sebanyak 4 orang, Dewasa Akhir menyukai jenis rantai besi dianyam kulit sebanyak 1 orang, Lansia Awal menyukai rantai besi dianyam kulit sebanyak 2 orang.

\section{Preferensi terhadap Penutup Tas :}

Remaja akhir lebih menyukai penutup tas jenis tidak berpenutup depan dan tutup depan setengah dengan kunci slot masing-masing 13 orang, Dewasa awal lebih menyukai Bentuk penutup Tas Tutup Lipat dengan Ritsleting di ujung dan magnet di dalam sebanyak 7 orang, Dewasa Akhir

Tabel 2. Suku

\begin{tabular}{|c|c|c|c|c|c|}
\hline & & Fiequency & Perconer & Vald Percent & Cumulative Peroent \\
\hline \multirow{9}{*}{ valid } & Juma & 22 & 30.6 & 306 & 30.6 \\
\hline & Dayak & 3 & 4.2 & 42 & 34.7 \\
\hline & Beniar & 18 & $25 . \mathrm{d}$ & 250 & 50.7 \\
\hline & Bugh & 9) & 12.5 & 12.5 & 722 \\
\hline & Podare & 4 & 5.6 & 58 & 778 \\
\hline & sunde & 3) & 4.2 & 42 & 81.9 \\
\hline & Kunai & 8 & 11.1 & 11.1 & 93.1 \\
\hline & Butak & 5 & 6.9 & es & 100.0 \\
\hline & Total & 72 & $100 \mathrm{~d}$ & $100 \mathrm{~d}$ & \\
\hline
\end{tabular}

Tabel 3. Usia * suku cosstrabulation

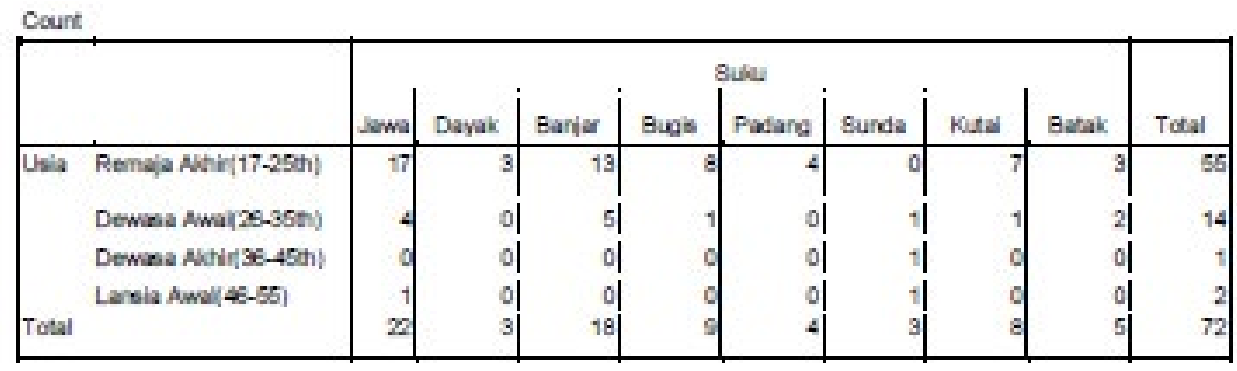


Vol. 7, No. 2, April 2020

menyukai penutup tas jenis tidak berpenutup depan 1 orang, Lansia Awal menyukai penutup tas jenis tidak berpenutup depan dan tutup depan setengah dengan kunci slot masing-masing 1 orang.

\section{Preferensi terhadap Kantong Tas :}

Remaja akhir lebih menyukai kantong tas jenis kantong dengan ritsleting 22 orang, Dewasa awal lebih menyukai kantong tas jenis kantong dengan ritsleting sebanyak 6 orang, Dewasa Akhir menyukai kantong tas jenis kantong dengan penutup dan kuncian diselipkan 1 orang, Lansia Awal menyukai kantong tas jenis kantong dengan penutup serta kancing jepret dan kantong dengan ritsleting masing-masing 1 orang.

\section{Preferensi terhadap Gusset/Bagian Samp- ing Tas :}

Remaja akhir lebih menyukai gusset tas jenis Bidang Diperluas Ada Ritsleting 16 orang, Dewasa awal lebih menyukai gusset tas jenis Sambungan dengan Tali dan Berkancing dan Bidang Diperluas Ada Ritsleting masing-masing sebanyak 4 orang, Dewasa Akhir menyukai kantong tas jenis Bidang Diperluas Ada Ritsleting 1 orang, Lansia Awal menyukai kantong tas jenis Bidang Diperluas Ada Ritsleting dan sambungan bersayap masing-masing 1 orang.

\section{Preferensi terhadap Material Tas :}

Remaja akhir lebih menyukai material gabungan ulap doyo dan kulit asli 29 orang, Dewasa awal lebih menyukai material gabungan ulap doyo dan kulit asli 29 orang, Lansia Awal menyukai material tas jenis gabungan ulap doyo dan kain kanvas 2 orang.

\section{Berdasarkan SUKU :}

\section{Preferensi terhadap Handel Tas :}

Suku Jawa lebih menyukai handel tas jenis ada gesper 6 orang, Suku Dayak lebih menyukai handel tas jenis ada gesper dan ada ring sebanyak 1 orang, Suku Banjar lebih menyukai Bentuk handle Tas rantai besi dan rantai besi dianyam kulit masing-masing sebanyak 4 orang, Suku Bugis lebih menyukai Bentuk handle Tas digulung 3 orang, Suku Padang lebih menyukai Bentuk handle Tas ada ring, ada gesper, rantai besi dan rantai besi dianyam kulit masing-masing sebanyak 1 orang, Suku Sunda lebih menyukai Bentuk handle Tas rantai besi dianyam kulit 3 orang, Suku Kutai lebih menyukai Bentuk handle Tas rantai besi dianyam kulit 4 orang, Suku Batak lebih menyukai Bentuk handle Tas pegangan di atas, ada ring masing-masing 2 orang.

\section{Preferensi terhadap Penutup Tas :}

Suku Jawa lebih menyukai penutup tas jenis Tutup Lipat dengan Ritsleting di ujung dan magnet di dalam 8 orang, Suku Dayak lebih menyukai penutup tas jenis tidak berpenutup depan, tutup depan setengah dan Tutup Lipat dengan Ritsleting di ujung dan magnet di dalam masing-masing 1 orang, Suku Banjar lebih menyukai penutup tas jenis Tutup Lipat dengan Ritsleting di ujung dan magnet di dalam sebanyak 6 orang, Suku Bugis lebih menyukai penutup tas jenis tutup depan setengah dengan kunci slot 3 orang, Suku Padang lebih menyukai penutup tas jenis tutup depan setengah dengan kunci slot sebanyak 3 orang, Suku Sunda lebih menyukai penutup tas jenis tidak berpenutup depan, tutup depan setengah, tutup depan setengah dengan kunci slot masing-masing 1 orang, Suku Kutai lebih menyukai penutup tas jenis tidak berpenutup depan 4 orang, Suku Batak lebih menyukai penutup tas jenis pegangan di atas, tutup depan setengah dengan kunci slot 2 orang.

\section{Preferensi terhadap Kantong Tas:}

Suku Jawa lebih menyukai kantong tas jenis kantong dengan ritsleting 12 orang, Suku Dayak lebih menyukai kantong tas jenis kantong dengan ritsleting 2 orang, Suku Banjar lebih menyukai kantong tas jenis kantong dengan ritsleting 6 orang, Suku Bugis lebih menyukai kantong tas jenis kantong dengan ritsleting 4 orang, Suku Padang 
Dita Andansari, Darius Shyafary, Hubungan Faktor Suku Dan Usia Dengan

Kecenderungan Preferensi Masyarakat Kalimantan Timur Terhadap Komponen

Produk Fesyen Tas

lebih menyukai kantong tas jenis kantong dengan penutup dan kuncian diselipkan 2 orang, Suku Sunda lebih menyukai kantong tas jenis kantong dengan penutup dan kuncian diselipkan 2 orang, Suku Kutai lebih menyukai kantong tas jenis kantong dengan penutup serta kancing jepret, kantong dengan penutup serta kancing tombol, kantong dengan ritsleting masing-masing 2 orang, Suku Batak lebih menyukai kantong tas jenis kantong dengan penutup serta kancing tombol, kantong dengan kuncian berkait masing-masing 2 orang.

\section{Preferensi terhadap Gusset/Bagian Samp- ing Tas :}

Suku Jawa lebih menyukai gusset tas jenis Bidang Diperluas Ada Ritsleting 8 orang, Suku Dayak lebih menyukai gusset tas jenis Bidang Diperluas Ada Ritsleting 1 orang, Suku Banjar lebih menyukai gusset tas jenis sambungan bersayap 6 orang, Suku Bugis lebih menyukai gusset tas jenis sambungan bersayap, Bidang Diperluas Ada Ritsleting, Sambungan dengan Tali dan Berkancing masing-masing 2 orang, Suku Padang lebih menyukai gusset tas jenis sambungan akordeon, sambungan umum dengan tali, Sambungan dengan Tali dan Berkancing, Bidang Diperluas Ada Ritsleting masing-masing 1orang, Suku Sunda lebih menyukai gusset tas jenis Bidang Diperluas Ada Ritsleting 3 orang, Suku Kutai lebih menyukai gusset tas jenis Sambungan dengan Tali dan Berkancing 4 orang, Suku Batak lebih menyukai gusset tas jenis Sambungan dengan Tali dan Berkancing 3 orang.

\section{Preferensi terhadap Material Tas :}

Suku Jawa lebih menyukai material gabungan ulap doyo dan kulit asli 12 orang, Suku Dayak lebih menyukai material gabungan ulap doyo dan kulit asli 2 orang, Suku Banjar lebih menyukai material gabungan ulap doyo dan kulit asli 8 orang, Suku Bugis lebih menyukai material gabungan ulap doyo dan kulit sintetis 5 orang, Suku Padang leb- ih menyukai material gabungan ulap doyo dan kulit asli 4 orang, Suku Sunda lebih menyukai material gabungan ulap doyo dan kulit asli 3 orang, Suku Kutai lebih menyukai material gabungan ulap doyo dan kulit sintetis 5 orang, Suku Batak lebih menyukai material gabungan ulap doyo dan kulit asli 4 orang.

\section{Analisis Tabulasi Silang}

Dalam penelitian ini, akan dicari hubungan antara tingkat keterkaitan antara suku dan usia dengan preferensi responden terhadap komponen tas wanita. Cara yang dilakukan adalah tabulasi silang antara pertanyaan tentang preferensi terhadap komponen tas wanita dengan tingkatan usia dan jenis suku responden. Tetapi tidak semua hasil dari tabulasi silang akan dianalisis, hasil yang akan dibahas adalah table tabulalsi silang yang memiliki nilai signifikansi chi square di bawah 0.05 .

Dari hasil pengolahan data, hanya terdapat 1 tabulasi silang yang signifikan, yaitu pada :Tingkat keterkaitan antara suku dengan bentuk kantong tas

Hasil lengkapnya dapat dilihat seperti tabel 4 berikut : 
Vol. 7, No. 2, April 2020

Tabel 4. Suku* Kantong Tas Crosstabulation

\begin{tabular}{|c|c|c|c|c|c|c|c|c|c|}
\hline & & & \multicolumn{6}{|c|}{ Kartong Tas } & \multirow[b]{2}{*}{ Total } \\
\hline & & & $\begin{array}{c}\text { Kartong } \\
\text { dengan } \\
\text { Penuhid } \\
\text { serta } \\
\text { KAncing } \\
\text { Jeored }\end{array}$ & $\begin{array}{c}\text { Kantone } \\
\text { dengan } \\
\text { Penuhus } \\
\text { senta } \\
\text { KAncina } \\
\text { Tombol }\end{array}$ & $\begin{array}{l}\text { Kartona } \\
\text { dergan } \\
\text { Kundian } \\
\text { Berikait }\end{array}$ & $\begin{array}{c}\text { Kankona } \\
\text { dengen } \\
\text { Penuhup } \\
\text { dan Cesper }\end{array}$ & $\begin{array}{c}\text { Kantong } \\
\text { dencan } \\
\text { Penuhup } \\
\text { dan Kuncian } \\
\text { Diselickan }\end{array}$ & $\begin{array}{l}\text { Kanbong } \\
\text { dengan } \\
\text { Poisleting }\end{array}$ & \\
\hline \multirow[t]{20}{*}{ 8.ku } & Jarma & Count & 1 & d & 1 & 7 & 1 & 12 & 22 \\
\hline & & $\begin{array}{l}\text { Expedted } \\
\text { Count }\end{array}$ & 28 & 24 & 1.8 & 3.7 & 24 & 8.9 & 220 \\
\hline & & \&isu wthin & 4.506 & $.0 * 1$ & $45 \%$ & 31.890 & 4.55: & $545 \%$ & 100.080 \\
\hline & & $\begin{array}{l}\text { K6 wthin } \\
\text { Kantong } \\
\text { Tin }\end{array}$ & | 11.196 & $.0 \%$ & $16.7 \%$ & 58.34 & $12.5 \mathrm{~s}$ & $41.4 \%$ & 30.690 \\
\hline & & K of Total & 1.436 & $.0 \%$ & $1.4 \%$ & 9.79 & 1.45 & $18.7 \%$ & 30.69 \\
\hline & Dayak & Count & 1 & d & 이 & d & 이 & 21 & 3 \\
\hline & & $\begin{array}{l}\text { Eepedted } \\
\text { Court }\end{array}$ & 4 & 3 & 3 & s & .31 & 1.2 & 30 \\
\hline & & $\begin{array}{l}* \text { win } \\
\text { sicu }\end{array}$ & | 33.394 & $.0 *$ & $.0 \%$ & .098 & ost & $68.7 \%$ & 100.098 \\
\hline & & $\begin{array}{l}\text { * winin } \\
\text { Kantong } \\
\text { Tas }\end{array}$ & | 11.196 & $.0 * 1$ & $.0 \%$ & .098 & $0 x$ & $6.9 \%$ & 4280 \\
\hline & & K of Total & 1.48 & $.0 * 1$ & $.0 \% 1$ & .095 & . 050 & $28 \% 1$ & 4.240 \\
\hline & Barjar & 'Count & & 3 & 21 & 3 & 이 & $6 \mid$ & $1 \mathrm{a}$ \\
\hline & & $\begin{array}{l}\text { Eoedted } \\
\text { Count }\end{array}$ & 23 & $2 d$ & 1.5 & $3 . d$ & 2이 & 7.3 & 180 \\
\hline & & \&oku wthin & 22.250 & 16.79 & $11.1 \%$ & +6.79 & 0s: & $33.3 \%$ & 100.058 \\
\hline & & $\begin{array}{l}\text { K werthin } \\
\text { Kartong } \\
\text { Tin }\end{array}$ & | 44.440 & 37.950 & $33.3 \%$ & 25.098 & ost & $20.7 \%$ & 25.098 \\
\hline & & SE of Total & 5.69 & 4.25 & $28 \%$ & 4298 & ost & 8.3\%| & 25.086 \\
\hline & Bughs & Count & 1 & 1 & 이 & 1 & 21 & 4 & G \\
\hline & & $\begin{array}{l}\text { Eepeded } \\
\text { Court }\end{array}$ & 1,1 & 1.0 & .8 & 1.5 & 1.0 & 3.6 & 90 \\
\hline & & $\begin{array}{l}8 \\
\text { soku }\end{array}$ & | 11.190 & 11.196 & $.0 \%$ & 11.19 & 22286 & $44.4 \%$ & 100.08 \\
\hline & & $\begin{array}{l}\text { \% winin } \\
\text { Kartong } \\
\text { Tin }\end{array}$ & 11.190 & 1250 & $.0 \%$ & 8.350 & 2508 & $13.8 \%$ & 12.598 \\
\hline & & \% of Total I & 1.430 & 1.490 & $.0 \%$ & 1.456 & 2854 & $5.6 \%$ & 12.59 \\
\hline
\end{tabular}


Dita Andansari, Darius Shyafary, Hubungan Faktor Suku Dan Usia Dengan

Kecenderungan Preferensi Masyarakat Kalimantan Timur Terhadap Komponen

Produk Fesyen Tas

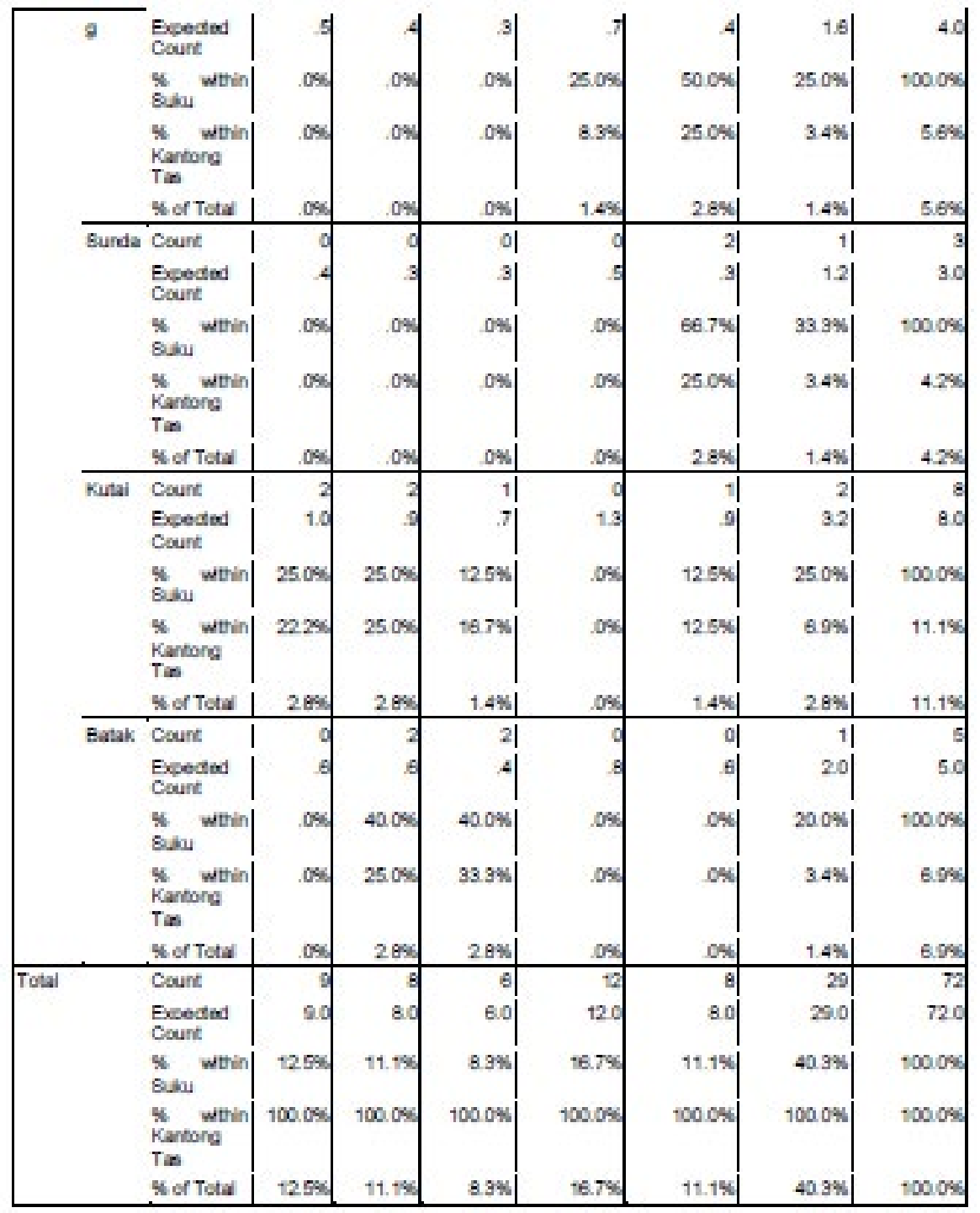

Tabel 5. Chi-Square Tests

\begin{tabular}{|c|c|c|c|}
\hline & Value & $d$ & $\begin{array}{c}\text { Asymp. } 8 \text { ia } / 2 \text {. } \\
\text { sided) }\end{array}$ \\
\hline Pearson Chi-Square & $51.739 *$ & 36 & .034 \\
\hline Hivelhood Rario & 51.520 & 36 & 005 \\
\hline Inearby Linear Association & 3.906 & 1 & 048 \\
\hline Nof Walid Cases & 72 & & \\
\hline
\end{tabular}

a. 28 cels $(95,8 \%)$ have exeeded count lese than 5 . The minimum expected court is 25 . 
Vol. 7, No. 2, April 2020

Pada table chi squre test, terbaca bahwa nilai chi square 0.034 , artinya di bawah 0.05 maka dapat diartikan bahwa terdapat pengaruh nyata antara tingkat keterkaitan suku dengan pilihan bentuk kantong tas.

Terlihat dari table di atas, bahwa Suku Jawa lebih memilih bentuk kantong tas dengan ritsleting, Suku Dayak memilih kantong tas dengan ritsleting, Suku Banjar memilih kantong tas dengan ritsleting, Suku Bugis memilih kantong tas dengan ritsleting, Suku Padang kantong dengan penutup dan kuncian diselipkan, Suku Sunda memilih kantong dengan penutup dan kuncian diselipkan, Suku Kutai mempunyai pilihan kantong tas yang berbeda, Suku Batak memilih kantong dengan penutup dan kuncian tombol berkait serta kantong dengan kuncian berkait. Dapat disimpulkan bahwa semua suku hamper sebagian besar memilih kantong tas dengan bentuk kantong tas dengan ritsleting, meskipun ada juga yang memilih selain bentuk kantong dengan ritsleting tetapi dalam jumlah yang sangat sedikit.

\section{KESIMPULAN}

Dari hasil analisis dapat disimpulkan bahwa :

1. Sebagian besar responden didomnasi oleh usia remaja akhir (17-25 thn) dengan $76,4 \%$, Suku Jawa yaitu 22 orang dengan $30,6 \%$.

2. Preferensi responden Handle tas yang disukai adalah rantai besi dianyam kulit $(25 \%)$, penutup tas yang disukai adalah tidak berpenutup depan sebesar $23,6 \%$, kantong dengan ritsleting sangat disukai yaitu $40,3 \%$, gusset/bagian sambungan samping tas dengan bentuk bidang diperluas ada ritsleting disukai sebesar $30,6 \%$ serta material yang disukai adalah material gabungan ulap doyo dan kulit asli sebesar $54,2 \%$.

3. Dari hasil pengolahan data, hanya terdapat 1 tabulasi silang yang signifikan, yaitu pada :

4. Tingkat keterkaitan antara suku dengan bentuk kantong tas

\section{Saran}

Perlu dilakukan penelitian lanjutan yaitu keterkaitan selain suku dan usia juga komponen kependudukan yang lain seperti pekerjaan dan pendapatan. Selain itu perlu diteliti keterkaitan faktor kependudukan tersebut dengan elemen estetika. 
Dita Andansari, Darius Shyafary, Hubungan Faktor Suku Dan Usia Dengan Kecenderungan Preferensi Masyarakat Kalimantan Timur Terhadap Komponen

Produk Fesyen Tas

\section{DAFTAR PUSTAKA}

Andansari, Dita \& Astagani,Asrina, 2016, Inovasi Desain Kerajinan Khas Kalimantan Timur sebagai Daya Saing Menghadapi MEA 2015, Kreatif: Jurusan Desain Polnes.

Lee, Yoon Kyung \& DeLong, Marilyn, 04 June 2018, Re-birthed fashion handbags as a collaborative design project

Raid \& Gopal,2014, Study of consumer buying behavior on Branded ethnic apparel , IOSR Journal of Business and Management e-ISSN: 2278-487X,p-ISSN: 23197668 PP 43-49

Leng \& Botelho, 2010, How does national culture impact on consumers decision-making style? a cross cultural study in Brazil, The United States an Japan. BAR,Braz. Adm. Rev. vol. 7 no. 3 Curitiba July/Sept. 2010

Nofiawaty, 2010, Hubungan Antara Faktor Penduduk Setempat Terhadap Kecenderungan Preferensinya, Jurnal Manajemen dan Bisnis Sriwijaya Vol. 8 No. 15 Juni 2010

https://kemenperin.go.id/

https://www.vogue.co.uk/gallery/bag-trends-by-the-decade

https://www. Shopee.com 